\title{
MITOLOGÍA, MEDICINA Y ENFERMERÍA EN LA GRECIA ANTIGUA
}

\author{
Pilar Darriba Rodríguez. Supervisora de Formación Continuada de Enfermería. \\ C.Hosp. "A.Marcide - Prof. Novoa Santos" Ferrol \\ S. Pedro de Leixa, s/n. 15405 - Ferrol (La Coruña) Telf: $981-334046$ \\ Dirección particular: \\ Santa Marina - Loureiro, $n^{\circ}$ 51. Ferrol - 15405 (La Coruña) \\ Telf: $981-371540$
}

\section{RESUMEN}

Buscando en los orígenes de la Historia podemos encontrar los inicios de la medicina o ciencia del curar y con ellos los inicios de la Enfermería; si nos remontamos a Grecia y sobre todo a su época clásica (siglo III al V a.C.) o también llamada de Pericles, observamos que se utilizaban palabras precursoras de las que hoy en día utilizamos en las ciencias de la saludo que incluso algunas son las mismas.

En este trabajo pretendo entroncar la mitología, la medicina y la enfermería de la Grecia clásica, para valorar su origen y su significado, demostrándo que estas ciencias se han desarrollado desde los orígenes de la humanidad y continuan en nuestros días, además, tal como se dice en diferentes ocasiones: un colectivo que conoce sus orígenes puede valorar mejor su presente y participar en su desarrollo de forma más efectiva.

\section{MEDICINE OR CARING SCIENCE IN ANCIENT GREECE}

\section{SUMMARY}

Looking back in history we could trace the onset of so called medicine or caring science, together with the onset of nursing. Returning to Greece and its classical period (3rd or 5th century B.C) or Pericles's century, we could observe they used the original words to those we use nowadays in the health sciences. Some of those words are even exactly the same.

The present study explores mythology, medicine and nursing in classical Greece, in order to evaluate its origin and meaning, and proving that those sciences have developed from the beginning of mankind to the present time. As has been said over and again: a collective who knows its origins could better evaluate its present, and participate in its further development in a more effective way.

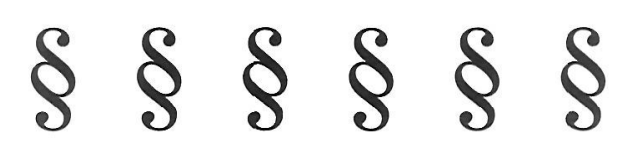


La Medicina racional no empírica, es decir, la que hoy conocemos como tal, parece ser que nació en la isla de Cos (Grecia), dónde la familia de los Asclepíades se transmitían los conocimientos de padres a hijos e incluso también a aprendices de Médico ajenos al genos.

Pero la Historia más antigua de Grecia se confunde con la Mitología, para los antiguos griegos no había demasiada diferencia entre lo divino y lo humano. Sus divinidades, aunque estaban en el Olimpo y eran inmortales, se relacionaban con los humanos y tenían algunas cualidades semejantes a ellos, y es más, algunos hombres por sus hazañas o por su origen, adquirían la categoría de semidioses y además algunas veces adquirían la inmortalidad uniéndose a los miembros del Panteón, que era la agrupación de todos los dioses.

El objetivo de este trabajo es buscar en los orígenes de la Medicina para encontrar y observar pa-

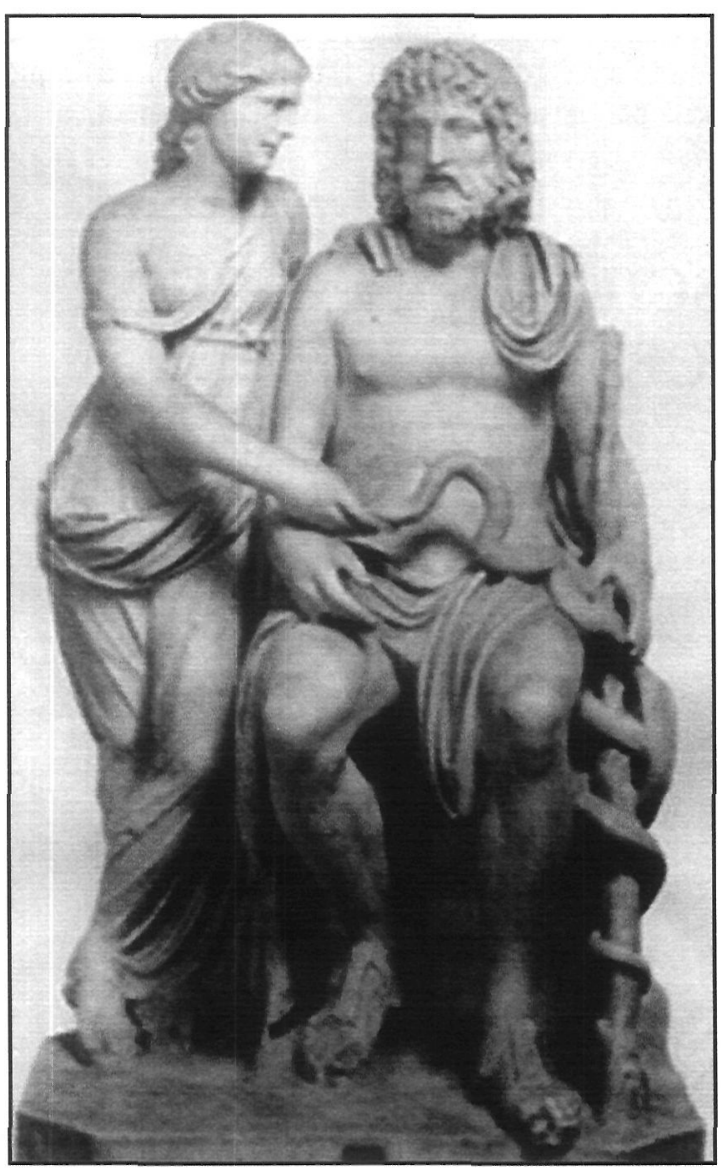

labras que hoy en día aún utilizamos, o sus precursoras, y valorar su origen y significado.

Entre las divinidades relacionadas con la Medicina se encuentra en primer lugar Apolo, inventor del arte de curar y médico de los dioses. En el juramento hipocrático, del que se hablará mas adelante, se decía (porque ya no se dice) en primer lugar: "Por Apolo el médico, y Esculapio, Panacea, e Higiea y todos los dioses y diosas a quienes llamo por testigos ..."

Apolo, que era hijo de Zeus y de Leto, nació en Delos y tuvo una hermana gemela: (en Roma fue conocida como Diana), diosa de los cazadores y de los arqueros, que dió su nombre a una planta medicinal, también era protectora de mujeres y niños, y en algunos lugares se conocía como la diosa de la muerte porque mataba sin piedad.

No se puede olvidar a Palas Atenea, diosa tutelar de Atenas y de sus habitantes, que fue escogida por su pueblo frente a Poseidon. Todo buen ateniense se encomendaba a ella antes de comenzar cualquier actividad. La diosa velaba por las familias y por la salud de todos ellos (en este caso era Atenea Higiea) En Roma fue conocida como Minerva.

Como dije antes los dioses tenían cualidades y actitudes humanas, y entre ellas destacaban las más elementales pasiones, así Apolo, que poseía una belleza radiante y una altura impresionante, y que además siempre andaba al acecho de mujeres bellas y a poder ser sin ropa, se enamoró de la ninfa Corónide ó Coronis (otras fuentes cuentan que Coronis era hija del Rey Flegias de Tesalia) y sobre la marcha la dejó embarazada. El padre de Coronis quiere que su hija se case con un pariente a lo que su hija acepta. Cuando Apolo se entera, por medio del cuervo que era el animal que le informaba de las cosas de la Tierra (el cuervo era de plumaje blanco, Apolo lo maldijo y desde aquella su plumaje es de color negro), mata al pariente-marido de la ninfa y, Artemisa mata a flechazos a Coronis y a sus amigas. Pero cuando Corónide está en la pira funeraria, aparece Apolo apesadumbrado y extrae del cuerpo muerto a su hijo no nacido al que llamaría Asclepio, 
y preocupado por su formación lo pone al cuidado del centauro Quirón, que le enseñaría el arte de curar.

Quirón ocupa un lugar aparte entre los centauros, se distinguía por su sabiduría y sus conocimientos. Nació de los amores de la ninfa Filira y el titan Cronos, que gobernó el universo hasta la llegada de Zeus y de las divinidades del Olimpo (Zeus era su hijo y luchó contra la tiranía de los titanes para apoderarse del poder divino), y tenía una extraña forma de centauro (mitad hombre mitad caballo) porque su padre había tenido que transformarse en caballo para enamorar a la ninfa y engendrarlo. Quirón recibío las enseñanzas de Apolo y Artemisa, que le dieron a conocer el arte de la Medicina y de la caza. Vivía en una gruta a los pies del monte Pelión, en Tesalia. Y rápidamente los pacientes acudieron a su consulta. Muchos héroes disfrutaron del privilegio de ser sus discípulos: Aquiles, Ulises, Diomédes,... y los argonáutas, en cuyo honor estableció un calendario marítimo. Quirón era inmortal, pero en un combate, Heracles lo hirió, por descuido, en el muslo con una flecha envenenada y el centauro atormentado por terribles dolores ofreció su inmortalidad a Prometeo, con el consentimiento de los dioses y murió.

Zeus puso a este centauro irreprochable entre los astros formando la constelación de Sagitario.

Pero volvamos a Asclepio o Esculapio para los romanos, cuya popularidad en la Grecia Antigua, en Roma y en países limítrofes fue muy grande. Asclepio aprendió del centauro el arte de curar y de elaborar remedios para curar, en poco tiempo llegó a tener una gran habilidad, y conseguía no solo curar a los enfermos sino que también resucitaba a los muertos, entonces Zeus, ante las protestas de Hades (dios del mundo subterráneo), fulminó a Asclepio con un rayo. A partir de entonces los hombres ascendieron a Asclepio a la categoría de dios olímpi$\mathrm{co}$, por lo que recibió honores divinos y gran número de enfermos, ciegos, paralíticos,... iban a adorarlo a sus santuarios (con una especial predilección por el de Epidauro) para solicitar su alivio o curación. Se decía que Asclepio se les aparecía en sueños y les revelaba el remedio para su curación.

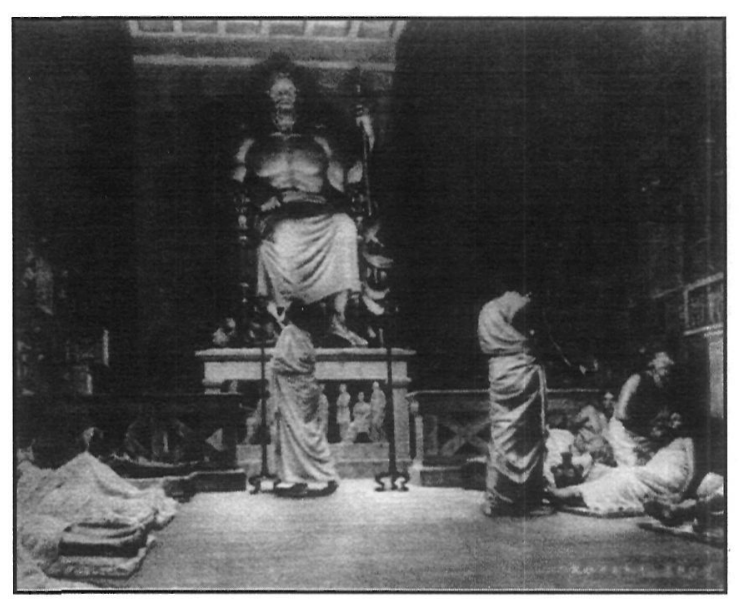

El emblema de Asclepio es el caduceo, un bastón con una serpiente enrrollada en él, (el motivo es que este animal es el símbolo de la renovación, ya que cambia de piel todos los años) y, aún hoy en día, es el símbolo universal de la Medicina.

Asclepio transmitió sus dotes y sus conocimientos a sus hijos, Macaón y Podalinio, pertenecientes al ejército griego; a su hija Higiea ó Higía, diosa de la salud y cuyo nombre perdura a través de la palabra Higiene, ella ayudaba a su padre en el cuidado de los enfermos y también en la curación de animales (esta diosa estaba rodeada de símbolos infernales y se la representa con una serpiente en la mano); también a su hija Panacea, que pertenece al grupo de divinidades que curan todas las enfermedades gracias a las hierbas, y desde entonces su nombre significa "la milagrosa medicina que cura todos los males"; así como a sus descendientes los Asclepíades, que formaban una fraternidad sacerdotal en la que los "secretos" ó conocimientos de su ilustre antepasado eran transmitidos de padres a hijos.

Aquí es dónde se enlaza la realidad (historia) con la leyenda (mitología), en los Asclepíades, de los que se habla al comienzo del trabajo, y que vivían en la isla de Cos. Ejercían su profesión en las puertas de los templos u otras veces de manera itinerante de pueblo en pueblo.

Los Asclepíades se ocuparon también de cuestiones filosóficas, llegando a establecer una estricta diferencia entre ciencia y religión, disyuntiva muy 
discutida a lo largo de todos los tiempos y aún hoy en día con polémica en ciertas ocasiones. También fundaron Escuelas de Medicina, y posiblemente fue en ellas dónde se institucionalizó el juramento, más tarde llamado hipocrático, para quienes finalizaban sus estudios.

Entre los hallazgos mas importantes de estas personas estaba el concebir la enfermedad no como una obra divina o demoníaca, sino como un proceso biológico, para lo que era necesario conocer el cuerpo humano (cosa muy difícil en la época, ya que por motivos religiosos no estaba permitida la disección de cadáveres, solamente se permitía en animales) y conocer los signos y síntomas de las enfermedades.

En el año 460 a. Cristo surgió la figura del ilustre Hipócrates de Cos,al que se considera el padre de la Medicina, ya que utilizaba un método basado en la observación y la razón y, también un verdadero "humanismo médico" todo ello expresado en el famoso juramento Hipocrático, que los médicos proclaman públicamente en una acto académico al finalizar sus estudios. A lo largo de los tiempos experimentó algunos cambios pero sigue teniendo el mismo trasfondo que en la Antiguedad.

Hipócrates y sus discípulos escribieron diversos libros que, hasta el final de la Edad Media, fueron la base del conocimiento médico: el "Corpus Hipocrático", dónde se recoge el saber médico de muchos años, aproximadamente un siglo.

Los médicos griegos sucesores de Hipócrates se llamaron iatros y fueron cada vez menos itinerantes en su trabajo. Se instalaron en las ciudades y recibían a sus pacientes en unas clínicas llamadas iatreion, que contaban con varias salas para exploraciones, para tratamientos, para operaciones,... además del instrumental necesario para todo ello.

Los aprendices de médicos se formaban con un maestro para aprender a diagnosticar y pronosticar, y a realizar diversas técnicas o terapias manuales como sangrías, aplicación de lavativas, colocación de ventosas y algunas operaciones quirúrgicas superficiales.
Podían obtenerse drogas del farmacopola (el farmacéutico de hoy en día) a quien le proporcionaba los materiales el rizotomo (cortador de raíces), aunque los médicos solían preparar ellos mismos los medicamentos que prescribían.

Las mujeres podían ser médicos, aunque normalmente se limitaban a ser enfermeras o comadronas. Muchas veces, por pudor, las mujeres dudaban en acudir al médico, sobre todo si se trataba de enfermedades íntimas, y les resultaba mas fácil acudir a una persona de su mismo sexo. Sócrates era hijo de una comadrona y, en su "Mayéutica" habla del arte de dar a luz a la mente, comentando extensamente esta profesión.

Según otras fuentes las mujeres en Grecia no podían iniciarse en los misterios de las Artes, pero por otro lado, hay testimonios de mujeres médicos como Agnódice, que tuvo que cortarse el pelo y vestirse de varón para poder estudiar con Herófilo, pero que más tarde fue reconocida por su labor y de Agámede, que se situa hacia el s. XII a.C., aunque ellas no fueron las únicas.

Una de las primeras citas dónde se nombra la labor de Enfermería es en los escritos hipocráticos, dónde se habla de asistentes o servidores (generalmente masculinos) como colaboradores del médico y que realizan prácticas que hoy decimos de

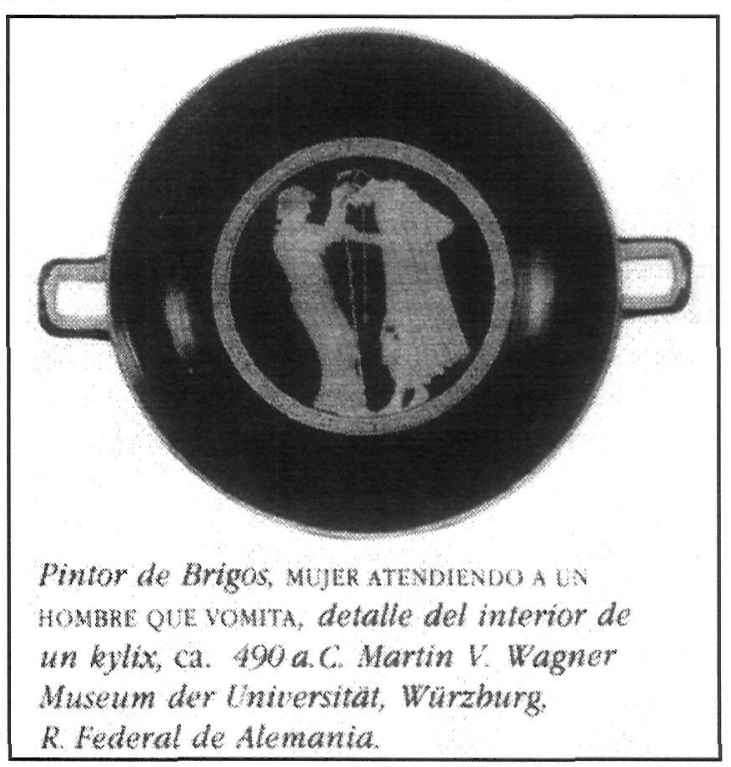


Enfermería como indicaciones dietéticas, higiene, baños terapéuticos, etc.

En general el papel de la mujer en Grecia se centraba en el hogar, pero hay referencias de las mujeres como cuidadoras y comadronas. En algunas ocasiones se la representaba bajo la figura de Panacea, (de la que ya hemos hablado) por lo que seleccionaban hierbas medicinales y ayudaban a los heridos y enfermos. En La Odisea aparece un relato de la esclava Euríclea a la que Ulises define como una buena enfermera. Pero, en general, no hay demasiados escritos sobre este tema dada la situación sociocultural de la mujer en la Grecia Clásica.

Referente a los médicos existían diferentes tipos:

- Los médicos públicos (demosioi iatroí), pertenecían a una institución comprobada y característica. En Atenas, la Asamblea de Ciudadanos elegía a los médicos públicos, que exponían ante ella sus títulos. Si eran elegidos la ciudad les retribuía, ponía a su disposición un local para consultar, operar u hospitalizar a los enfermos y el Estado pagaba las medicinas. Estos gastos se cubrían con un impuesto especial llamado iatricón.

- Los médicos militares, que estaban con los ejércitos durante las guerras o campañas curando a los heridos, como se cuenta en La Ilíada.

- Los pedotribas, que no eran médicos pero ejercían una "medicina de gimnasio". Desde su papel de instructores, eran a la vez higienistas y dietistas, aconsejando a los gimnastas sobre el mejor régimen dietético, siendo masajistas, ayudando a reducir fracturas, luxaciones o esguinces. Y algunas veces, como Heródico de Selimbria, después de ser pedotriba durante bastante tiempo se hacían médicos como algo lógico y normal.

- Los médicos con ejercicio libre, como actualmente la medicina privada.
La Medicina griega, al igual que la cultura helénica, pasó casi íntegra a Roma y desde allí constituiría la base fundamental de la ciencia médica en Europa durante muchísimos años.

Como vemos en Grecia ya existían Cuidados de Enfermería y algunas de sus costumbres aún perviven hoy en día (claro que con algunas variaciones) y muchas de las palabras que conocemos y utilizamos actualmente tienen su origen en la Grecia Clásica. Este trabajo pretende servir para conocer someramente parte de nuestros orígenes, ya que en estas raíces está la base de nuestra profesión, la Enfermería.

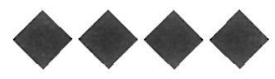

BIBLIOGRAFÍA:

Arana, JI. (1994) Historias curiosas de la medicina. Escasa Calpe, Madrid.

Arnaud, M. (1994) La mitología clásica. Acento, Madrid.

Flaceliere, R. (1993) La vida cotidiana en Grecia en el siglo de Pericles. Temas de Hoy, Barcelona.

Garcia Barros S; Calvo Charro E. (1992) Historia de la enfermería. Secretariado de Publicaciones Universidad de Málaga, Málaga.

Hernández Conesa J. (1995) Historia de la enfermería. Un análisis histórico de los cuidados de Enfermería. Interamericana McGraw - Hill, Barcelona.

Donahue P. (1985) Historia de la enfermería. Doyma, Barcelona.

Schmidt, J. (1995) Diccionario de mitología griega y romana. Larousse Planeta, Barcelona. 